\title{
Treatment of Esophageal Cancer with High Dose Rate Intracavitary Irradiation
}

\author{
Mitsunobu Abe and Toshio Kitagawa* \\ Department of Radiology, National Defense Medical College, \\ Tokorozawa 359 and *National Cancer Center, Tokyo 104
}

\begin{abstract}
Aвe, M. and Kitagawa, T. Treatment of Esophageal Cancer with High Dose Rate Intracavitary Irradiation. Tohoku J. exp. Med., 1981, 134 (2), 159-167Fifteen patients with esophageal cancer were treated with high dose rate intracavitary irradiation from a small radioactive source. The apparatus used for the intracavitary irradiation consisted of a remote-control intracavitary irradiation apparatus with small high intensity source (Ralstron, Shimazu Co.) and a transfer tube of radioactive source. Since the field size of irradiation was various, the most suitable program was set up at the depth of $0.5 \mathrm{~cm}$ from the inner surface of the esophagus. 13 fresh cases were treated with high dose rate intracavitary irradiation of 1000-2750 rads $(0.5 \mathrm{~cm}$ below the inner surface) after external irradiation of ca. 5000 rads with Linac x-ray. As a result, 7 cases survived 1 year and 1 case 2 years. Local recurrence was seen in 5 out of 7 cases surviving 1 year. 2 recurrence cases after radical external irradiation showed improvement on $\mathrm{x}$-ray picture through intracavitary irradiation. - radiotherapy; esophageal cancer; intracavitary irradiation
\end{abstract}

One of the reasons for unfavorable results of radiation therapy of esophageal cancer lies in the low rate of local curability (Pearson 1969, 1971; Kato et al. 1975; Usui et al. 1975; Mikuriya et al. 1976). The authors recognized the rest of lesions at the end of irradiation and the recurrence of primary lesions (sites of irradiation) within 18 months in $84 \%$ of 51 cases treated with more than 6000 rads given by conventional external irradiation (Abe et al. 1976). It may be attributable to deficient irradiation dosage. However, in treating esophageal cancer with external irradiation alone, the dose is restricted because of anatomical peculiarity of the esophagus, and it is difficult to irradiate a sufficient dose to cure esophageal cancer completely. To supplement shortage of dose in external irradiation, intracavitary irradiation is considered using a small radioactive source. Therefore, in order to improve the rate of local curability of esophageal cancer, boost therapy was tried by combining external irradiation with intracavitary irradiation by a high intensity small radioactive source. This paper deals with the method and results of this combined irradiation therapy.

\section{Materials and Methods}

\section{Materials}

Esophageal cancer was treated by intracavitary irradiation with a high intensity small

Received for publication, July 7, 1980. 
radioactive source in 13 fresh cases and 2 recurrence cases after radical external irradiation, 15 cases in total. All cases had squamous cell carcinoma. They consisted of 11 males and 4 females, average age being 69 years. As control, such cases were selected which showed nearly uniform extensibility of the local esophageal wall by slight air pressure under intracavitary irradiation.

Methods

Fig. 1 shows a typical method of treating a fresh case with this method.

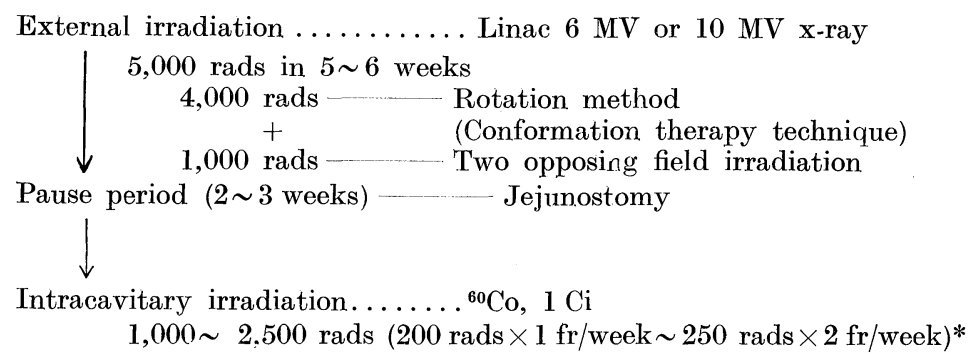

Fig. 1. Method of boost therapy combinining external irradiation with intracavitary irradiation. *Dose at the point $5 \mathrm{~mm}$ in depth from the esophageal wall-surface.

External irradiation. For external irradiation $6 \mathrm{MV}$ Linac $\mathrm{x}$-ray was used in most cases, and $10 \mathrm{MV}$ Linac x-ray in some cases. In principle, broad irradiation field was used for the primary lesion, 4000 rads with rotation irradiation (conformation irradiation technique) and 1000 rads with anterior and posterior 2 portal opposing fields irradiation; 5000 rads in total were irradiated in 5-6 weeks. Both supraclavicular fossae were irradiated simultaneously with anterior and posterior 2 opposing ports to nearly the same dose.

Jejunostomy. In the pause period after external irradiation, jejunostomy was performed. It was in accordance with the policy to avoid oral food intake to protect the local part from mechanical and chemical irritations during the period of the intracavitary irradiation.

Intracavitary irradiation. Intracavitary irradiation was started 2-3 weeks after termination of external irradiation. The apparatuses used for intracavitary irradiation are remote-control high intensity small source intracavitary irradiation apparatuses (Ralstron, Shimazu Co.) and a source transfer tube connected with the former. Ralstron has a small particle of $1 \mathrm{~mm}$ diameter enclosed in a capsule (ca. $1 \mathrm{Ci} \mathrm{Co-60)}$ ) as a radioactive source, and by remote control the radioactive source can stay at any point for any length of time within the length of $15 \mathrm{~cm}$. The source transport tube is a polyethylene blind tube (main tube), $65 \mathrm{~cm}$ in length, at the tip of which a small lead piece is enclosed for position identification at roentgenoscopy, and then ca. $15 \mathrm{~cm}$ rubber pouch is attached. The rubber pouch dilates with air blown in through a small tube attached in parallel to the main tube so that the center of the main tube (radiation source) comes to lie $1.0 \mathrm{~cm}$ from the surface of the esophageal cavity.

The length of esophageal cancer focus was various, and the followings were considered to establish irradiation conditions with high dose small source intracavitary irradiation.

Dose in the course of transport of the source. Since the speed of the radiation source transferred from the storage container to the site of treatment was ca. $15 \mathrm{~cm} / \mathrm{sec}$, the time required to pass the sphere of treatment was less than 1 sec. As the influence of the dose in this passage was less than ca. $0.3 \%$ on the calculation of dose distribution in the sphere of treatment, this dose was neglected concerning the dose distribution calculation.

Number of stops of the radiation source and calculation of dose distribution. Stops of the radiation source could be set up within 5 points from the construction of this apparatus, and the radiation source could be regarded as point source for calculation in this case. When $n$ represents the number of stops to be set up for the radiation source, the absorbed 
dose $D_{p}$ at the point $(r, z)$ is expressed by the following formula:

$$
D_{p}(r, z)=\sum_{i=1}^{n} \frac{46 t_{i}}{4 \pi\left\{r^{2}+\left(z_{i}-z\right)^{2}\right\}} \operatorname{WAR}\left(\sqrt{r^{2}+\left(z_{i}-z\right)^{2}}\right)
$$

where $r$ is a distance from the axis of movement of the radiation source (called $Z$ axis in the following), and $z$ is a distance from the center of treatment sphere parallel to $Z$ axis. $z_{i}$ represents coordinates of the $i$ th point of stop, and $t_{i}$ represents the established time of stay at this point (sec). WAR $(r, z)$ represents the ratio of irradiation dose in water to irradiation dose in air at the distance of point $(r, z)$ from the radiation source.

Next, the speed of transfer of the radiation source on returning between any two stops is $0.4 \mathrm{~cm} / \mathrm{sec}$, and the contribution to the dose distribution cannot be neglected if the length of treatment by the small source is long. Therefore, calculation of the contribution to the dose distribution is approximated by the following formula, regarding the source as linear:

$$
D_{L}(r, z)=\frac{46 \times 2.5}{4 \pi r}\left\{\tan ^{-1}\left(\frac{z_{1}-z}{r}\right)-\tan ^{-1}\left(\frac{z_{n}-z}{r}\right)\right\} .
$$

Where $D_{L}$ is absorbed dose at the point $(r, z)$. Formulas (1) and (2)are obtained at the unit of $R$ for the source 1 Ci Co-60.

The most suitable space dose distribution. The most suitable space dose distribution was considered uniform dose distribution at the depth of a specified focus within the sphere of treatment. When COV becomes the minimum,

$$
\mathrm{COV}=\frac{D_{\max }-D_{\min }}{\left(D_{\max }+D_{\min }\right) / 2}
$$

where COV is the rate of dose change in the designated sphere, the condition is used as criterion to set up the most suitable program.

The rate of contribution of formula (2) to total irradiation dose depends on the treatment sphere and the planned dose, and is independent of the time of stop at each point. Therefore, from (1) the distribution of the most suitable stop time at each number of stop is obtained as function of distance from the source axis at each distance between stop points. Further, the rate of change is obtained. On the basis of these results, considering both formulas (1) and (2), the conditions to set up the most suitable program are obtained when the most suitable space dose distribution is obtained in accordance with the treatment plan in which the value of (3) becomes the minimum.

Table 1 shows the most suitable program to irradiate the lesion with 250 rads, when $\mathrm{Co}-60 \mathrm{I} \mathrm{Ci}$ is used as a small source, and the distance is $1.5 \mathrm{~cm}$ between the source and the lesion. Fig. 2 is an isodose curve in accordance with the most suitable program of this method for the treatment sphere of $5 \mathrm{~cm}$.

\begin{tabular}{|c|c|c|c|c|c|c|c|c|}
\hline & \multicolumn{8}{|c|}{ Treatment length $(\mathrm{cm})$} \\
\hline & 3 & 4 & 5 & 6 & 7 & 8 & 9 & 10 \\
\hline Number of stops & 3 & 3 & 4 & 4 & 5 & 5 & 5 & 5 \\
\hline Space $(\mathrm{mm})$ & 14 & 19 & 16 & 19 & 17 & 19 & 22 & 24 \\
\hline Setting time (sec) $t_{1}$ & 114 & 118 & 109 & 114 & 109 & 114 & 115 & 120 \\
\hline$t_{2}$ & 35 & 66 & 59 & 73 & 61 & 71 & 83 & 89 \\
\hline $\mathrm{t}_{3}$ & 114 & 118 & 59 & 73 & 63 & 73 & 84 & 90 \\
\hline$t_{4}$ & & & 109 & 114 & 61 & 71 & 83 & 89 \\
\hline$t_{5}$ & & & & & 109 & 114 & 115 & 120 \\
\hline Maximum dose (rads) & 256 & 255 & 256 & 258 & 256 & 259 & 259 & 263 \\
\hline Minimum dose (rads) & 243 & 245 & 243 & 243 & 244 & 241 & 241 & 239 \\
\hline
\end{tabular}

TABLE 1. Examples of optimum programing condition for a dose of 250 rads over the effective treatment length at $1.5 \mathrm{~cm}$ away from source axis

Source strength: ${ }^{60} \mathrm{Co}-1 \mathrm{Ci}$. 


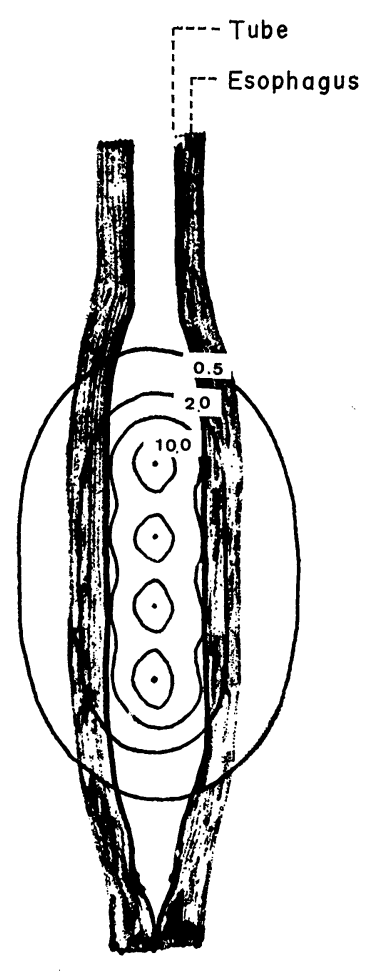

Fig. 2. Isodose curves on 4 points irradiation in the esophagus cavity. Numbers indicate given dose ( $\times 100$ rads). Effective length, $5 \mathrm{~cm}$. Space in each two points, $16 \mathrm{~mm}$. Exposure time, 92 50, 50, 92 sec.

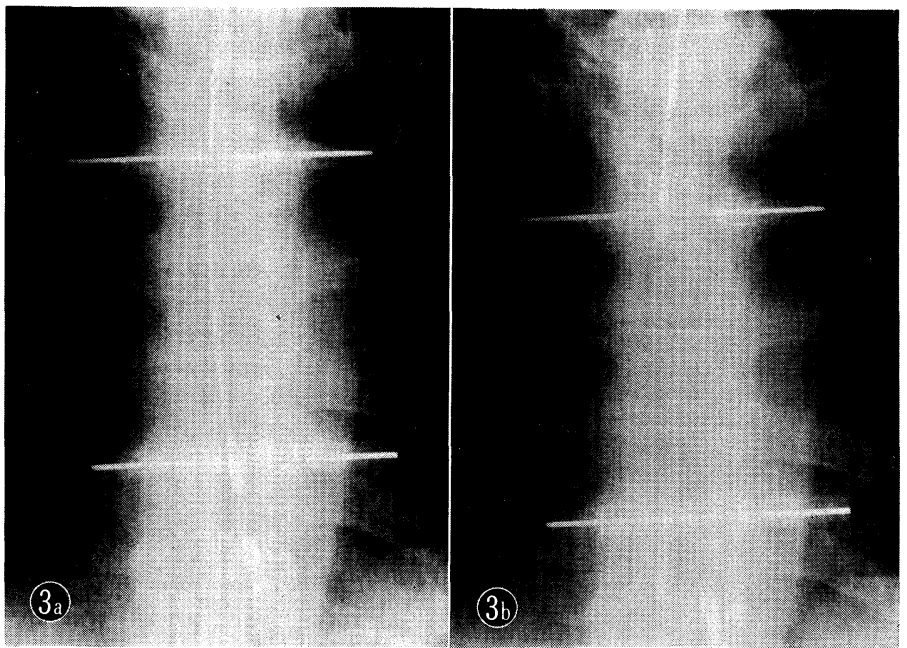

Fig. 3. Radiographs of esophagus showing dummy source in position. a: Dummy source at the first point in the sphere of treatment.

b: Dummy source at the final point in the sphere of treatment. 
Actually, at the commencement of external irradiation, from x-ray picture, roentgenoscopic finding, etc., the anterior chest wall skin is marked at the heights corresponding to the upper and lower ends of the lesion at the same posture as in cases of intracavitary irradiation, and from this mark the limit of the remaining lesion is judged and determined at the start of intracavitary irradiation. Next, guided by the lead piece attached to the tip of the source transport tube that is swallowed down, mutual relation between the tube and the focus is confirmed through roentgenoscopy,comparing with the mark on the skin, then the tube is fixed at the lesion by blowing air into the rubber pouch outside the transport tube, and the tube is fixed simultaneously in the oral cavity with a mouth-piece. While a dummy source is moved automatically in the tube under the same condition as in cases of irradiation to confirm that the source moves in the focus sphere as planned. Then intracavitary irradiation is administered in accordance with the established program.

Fig. $3 a$ is an $x$-ray picture of dummy source kept at the first point of the irradiation conditions, and Fig. $3 b$ is an $x$-ray picture of it at the final point.

\section{RESULTS}

The results are shown in Table 2. The dose of intracavitary irradiation is at the depth of $0.5 \mathrm{~cm}$ from the inner surface of the esophagus. Among 13 fresh cases, 7 cases survived 1 year, and 1 case more than 2 years. It was not good results, though some died of other diseases such as apoplexy (Cases 2 and 6) and heart disease (Case 8). Local recurrence was seen in 5 out of 7 cases surviving 1 year.

In Cases 14 and 15 intracavitary irradiation was conducted on recurrent lesion after external irradiation for radical cure. Both cases showed improvement in $\mathrm{x}$-ray picture after intracavitary irradiation.

x-Ray pictures of Cases 5, 6 and 15 are shown.

Case 5. 69 years old, female. After external irradiation of $4940 \mathrm{rads} / 5$ weeks

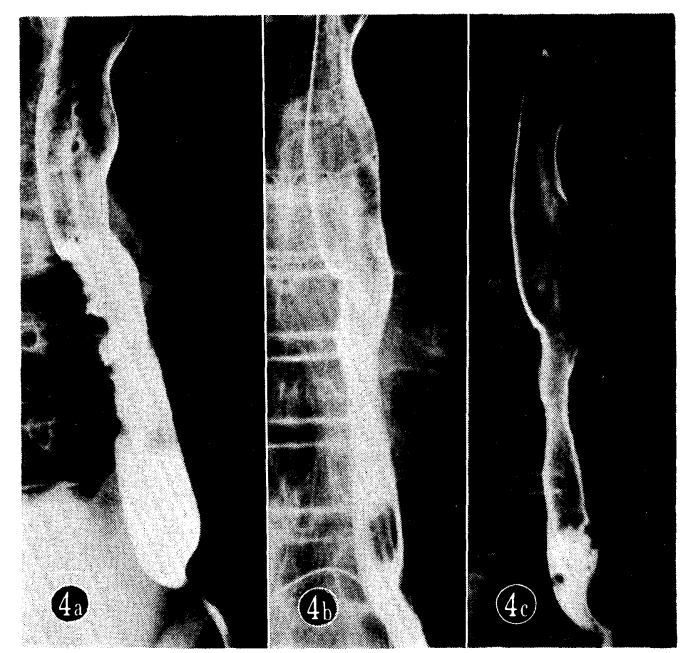

Fig. 4. Squamous cell carcinoma of the middle and lower thoracic esophagus.

a: Pretreatment.

b: 4950 rads with external irradiation.

c: Immediately after completion of intracavitary irradiation. The barium pattern was much smoother. 
TABLE 2. Results of

\begin{tabular}{|c|c|c|c|c|c|c|c|}
\hline \multirow[b]{2}{*}{ Case } & \multirow{2}{*}{ Sex } & \multirow{2}{*}{ Age } & \multicolumn{3}{|c|}{ Primary lesion } & \multicolumn{2}{|c|}{ External irradiation } \\
\hline & & & Location§ & $\begin{array}{c}\text { Length } \\
\text { (cm) }\end{array}$ & Type & $\begin{array}{l}\text { Total dose } \\
\text { (rads) }\end{array}$ & $\begin{array}{c}\text { Duration } \\
\text { (weeks) }\end{array}$ \\
\hline 1 & M & 61 & Ce. Lu & 6 & Spiral & 5000 & 5 \\
\hline 2 & M & 80 & $\operatorname{Im}$ & 5 & Spiral & 5030 & 6 \\
\hline 3 & M & 77 & Ei. Ea & 6 & Serrated & 5000 & 5 \\
\hline 4 & M & 66 & $\operatorname{Im}$ & 6 & Spiral & 5130 & 6 \\
\hline 5 & $\mathbf{F}$ & 69 & Im. Ei & 9 & Spiral & 4940 & 5 \\
\hline 6 & M & 74 & $\operatorname{Im}$ & 7 & Spiral & 4620 & 5 \\
\hline 7 & $\mathrm{M}$ & 68 & Im. Ei & 13 & Spiral & 5090 & 7 \\
\hline 8 & M & 58 & Im & 4.5 & Serrated & 5000 & 5 \\
\hline 9 & M & 71 & Iu. Im & 5.5 & Serrated & 5000 & 5 \\
\hline 10 & $\mathrm{~F}$ & 54 & $\operatorname{Im}$ & 8 & Sprial & 5040 & 5 \\
\hline 11 & $\mathbf{F}$ & 63 & $\mathrm{Im}$ & 6 & Sprial & 5150 & 5.5 \\
\hline 12 & $\mathrm{M}$ & 73 & $\mathrm{Im}$ & 6 & Tumorous & 5090 & 5.5 \\
\hline 13 & $\mathrm{~F}$ & 80 & Im. Ei & 9 & Spiral & 5300 & 9 \\
\hline$* 14$ & M & 67 & $\mathrm{Im}$ & 6 & Serrated & 6400 & 8 \\
\hline$* 15$ & M & 75 & Im. Ei & 12 & $\therefore$-Spiral & 7660 & 9 \\
\hline
\end{tabular}

* Intracavitary irradiation to local recurrence after radical external radiotherapy $\uparrow$ Died of causes not directly related to the esophageal cancer.

$\ddagger$ Months from the completion of external irradiation.

$\S \mathrm{Ce}$, cervical esophagus; Iu, upper intra-thoracic esophagus; Im, middle intra-

with Im Ei, $9 \mathrm{~cm}$ spiral type, intracavitary irradiation of 1950 rads was given. $\mathrm{x}$-Ray pictures are shown before treatment (Fig. 4a), after external irradiation (Fig. 4b) and after intracavitary irradiation (Fig. 4c).
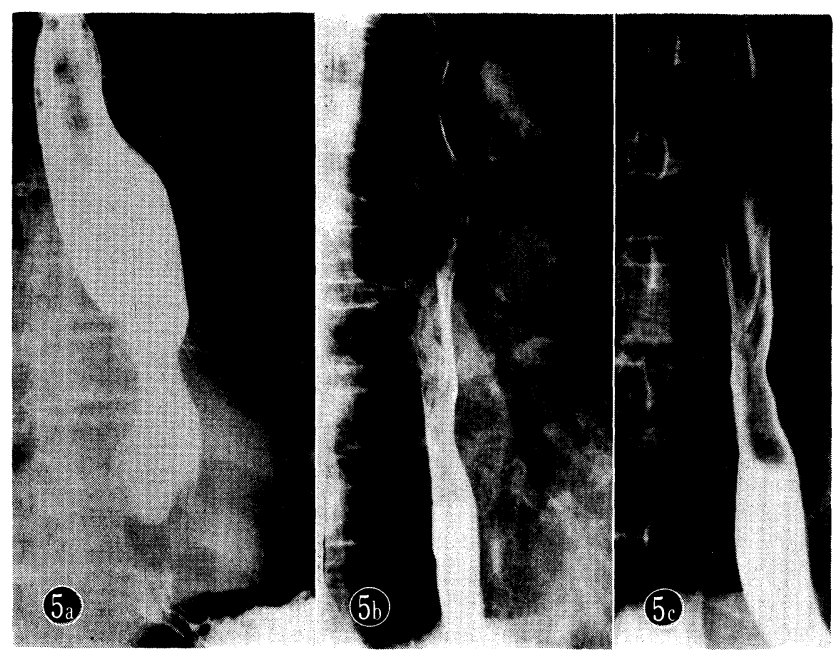

Fig. 5. Squamous cell carcinoma of the middle thoracic esophagus.

a: Pretreatment.

b: 4620 rads with external irradiation.

c: Immediately after completon of intracavitary irradiation. The barium pattern was almost normal. 
intracavitary irradiation

\begin{tabular}{|c|c|c|c|c|}
\hline \multicolumn{3}{|c|}{ High dose rate intracavitary irradiation } & \multirow{2}{*}{$\begin{array}{l}\text { Clinical follow-up } \\
\text { (months) }\end{array}$} & \multirow{2}{*}{$\begin{array}{l}\text { Survival } \\
\text { (months) }\end{array}$} \\
\hline $\begin{array}{l}\text { Total dose } \\
\text { (rads) }\end{array}$ & $\begin{array}{l}\text { Duration } \\
\text { (weeks) }\end{array}$ & $\begin{array}{l}\text { Fractionation } \\
\text { (rads/week) }\end{array}$ & & \\
\hline 1000 & 3 & $200 \times 1$ & Local recurrence (8) & Dead (16) \\
\hline 1000 & 3 & $250 \times 1$ & & Dead $\uparrow(5)$ \\
\hline 1000 & 3 & $250 \times 1$ & Local recurrence $(5)$ & Dead (20) \\
\hline 1950 & 7 & $250 \times 1$ & Local recurrence (7) & Dead $(20)$ \\
\hline 1950 & 7 & $\begin{array}{l}200 \times 2 \\
250 \times 1 \\
200 \times 2\end{array}$ & & Dead (11) \\
\hline 1200 & 2.5 & $200 \times 2$ & & Dead $\uparrow(13)$ \\
\hline 2750 & 7 & $250 \times 2$ & Local recurrence $(6)$ & Dead ( 8) \\
\hline 2500 & 5.5 & $250 \times 2$ & Stomach cancer & $\operatorname{Dead} \uparrow(13)$ \\
\hline 1250 & 2.5 & $250 \times 2$ & Lumg metastasis & Dead (4) \\
\hline 2500 & 5 & $250 \times 2$ & Local recurrence (12) & Dead (26) \\
\hline 1250 & 2 & $250 \times 2$ & Local recurrence (8) & Dead (13) \\
\hline 2250 & 5 & $250 \times 2$ & & Dead (11) \\
\hline 1250 & 5 & $250 \times 1$ & & Alive (10) \\
\hline 1250 & 2.5 & $250 \times 2$ & Local recurrence $(2)_{\ddagger}^{\ddagger}$ & Dead (6) \\
\hline 2250 & 5 & $250 \times 2$ & Local recurrence $(3) \ddagger$ & Dead (16) \\
\hline
\end{tabular}

was administered.

thoracic esophagus; Ei, lower intra-thoracic esophagus; Ea, abdominal esophagus

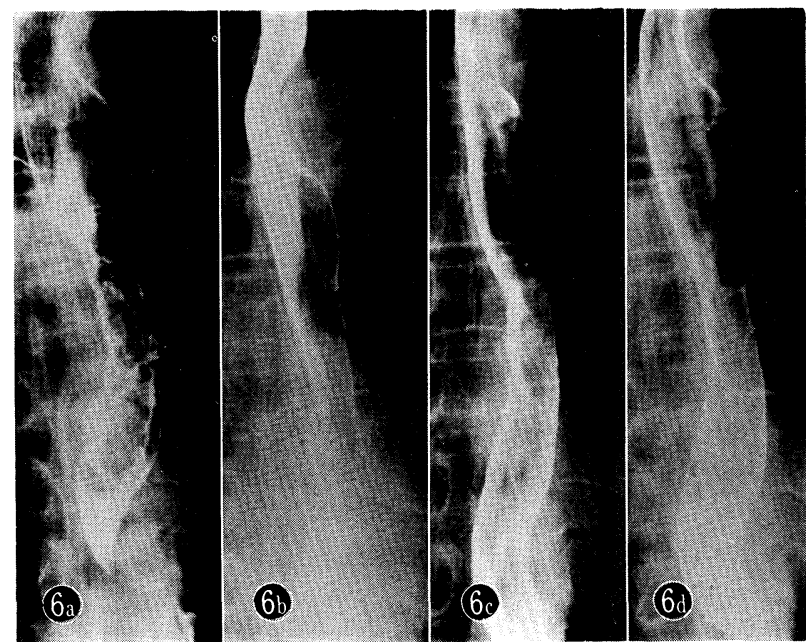

Fig. 6. Squamous cell carcinoma of the middle and lower thoracic csophagus.

a: Pretreatment.

b: Immediately after external irradiation with 7600 rads. There was excellent regression of the lesion and no evidence of the residual.

c: 3 months after completion of external irradiation. The roentgenographic appearance suggested the presence of recurrent carcinoma.

d: Immediately after intracavitary irradiation to the recurrent focus. The barium pattern was almost normal. 
Case 6. 74 years old, male. After external irradiation of 4620 rads with Im, $7 \mathrm{~cm}$ spiral type, intracavitary irradiation of $1200 \mathrm{rads}$ was given. Without local recurrence the patient died of apoplexy after 13 months. $x$-Ray pictures are shown before treatment (Fig. 5a), after external irradiation (Fig. 5b), and after intracavitary irradiation (Fig. 5c).

Case 15. 75 years old, male. Through external irradiation of $7660 \mathrm{rads} / 9$ weeks with Im Ei, $12 \mathrm{~cm}$ spiral type (Fig. 6a), marked improvement was seen in $\mathrm{x}$-ray picture (Fig. 6b), but recurrence was seen after 3 months (Fig. 6c). Intracavitary irradiation 2250 rads was given, and the recurrent focus disappeared in x-ray picture (Fig. 6d).

\section{Discussion}

Poor radiotherapeutic results of esophageal cancer are attributable to failure in the local treatment of primary lesion. Those tumor cells which were not eradicated by external irradiation become a factor in recurrence. Iizuka (1969) stated, from histopathological findings of excised specimens from 117 cases of preoperative irradiation, that irradiation leaves a few cancer cells on the external coat of the esophagus, but more on the mucous membrane, if cancer cells are left. Abe et al. (1976) stated that, from histological examination, remaining foci were seen in the specimens scattered like hive in the sphere of less than $0.5 \mathrm{~cm}$ from the internal mucosal surface of the esophagus in 18 of 19 cases of favorable progression on the wall being not recognized clear foci remaining in the lumen of the esophagus at the end of 5000 rads irradiation from x-ray and endoscopic findings. From the above results, for cancer cells remaining after a certain dose of external irradiation and recurrent foci recognized early, treatment with a small radioactive source showing dose distribution as in Fig. 2 seems effective in improving the result of radiotherapy of esophagus cancer.

To carry out this method, there are such problems to be solved as determination of indications, single irradiation dose, fractionation, total dose, etc. It is not indicated when the focus lies too deep from the internal surface of the esophagus from dose distribution of the small radiation source, but is indicated when it is within $0.5 \mathrm{~cm}$. Concerning the dose, with reference to high dose rate intracavitary irradiation for cervical cancer (Arai and Morita 1974; Arai et al. 1976), it was started with a weekly dose of $200 \mathrm{rads}$, increased gradually to $250 \mathrm{rads} \times 2 /$ week, and the total dose was increased to 2000-2500 rads in conformity with it. However, from the experience on 12 cases, Case 13 has been treated with weekly dose of 250 rads and total dose of 1250 rads, and the course is now under observation.

Good results of Haruyama et al. (1977) and Nishio et al. (1978) are worthy of attention, in which, after external irradiation of 5000 rads, a single dose of 1000$1500 \mathrm{rads}$ (dose on the surface of the esophageal lumen by an after loading technique using $\mathrm{Ra} 10 \mathrm{mg}$ 4-5 tubes) was irradiated twice in 2 weeks (among 23 cases, local control $65 \%$ and 2 year survival 43\%). Kaneta et al. (1968) and Usui et al. (1975) reported also 5-year survival cases with small source intracavitary 
irradiation in addition to external irradiation. Namely, intracavitary irradiation as additional irradiation is excellent because the dose can be concentrated in the lesion remaining after external irradiation, and is considered an effective treatment in selected indications.

Judging from biological consideration, as stated by Hall and Phil (1972), the therapeutic ratio becomes less with high dose rate irradiation than with low dose rate one, and we think high dose intracavitary irradiation should be performed more carefully.

\section{References}

1) Abe, M., Ishigaki, T., Nakamura, K., Ushiro, S., Kitagawa, T., Kawachi, K., Matsumoto, K., Hirota, E., Sano, R. \& Iizuka, T. (1976) Intracavitary irradiation technique applied on radical radiation treatment of the esophageal cancer. Nippon Acta radiol., 36, 111-120. (Japanese)

2) Arai, T. \& Morita, S. (1974) The treatment of cervix cancer with high dose rate intra-cavitary irradiation. Jap. J. Cancer Clin., 20, 33-36. (Japanese)

3) Arai, T., Morita, S. \& Kurisu, A. (1976) Comparison of radiation complication between low dose rate and high dose rate intracavitary irradiation in cervix cancer. Jap. J. Cancer Clin., 22, 1417-1423. (Japanese)

4) Hall, E.J. \& Phil, A.M. (1972) Radiation dose-rate a factor of importance in radiobiology and radiotherapy. Brit. J. Radiol., 45, 81-97.

5) Hareyama, M., Sakurai, T., Nishino, M., Koizumi, Y., Moriya, H., Koshiba, R., Hamada, M., Ibayashi, J. \& Fujita, M. (1977) Radiotherapy of esophageal cancer combined with external beam and intracavitary radium therapy. Jap. J. Cancer Clin., 23, 1199-1205. (Japanese)

6) Iizuka, T. (1969) Treatment of esophageal cancer. Jap. J. Cancer Clin., 15, 297-301. Japanese)

7) Kaneta, K., Okano, S., Goto, H., Sawaki, S. \& Tsuya, A. (1968) Results of radiation therapy of the middle third esophageal cancer. Jap. J. Cancer Clin., 14, 860-870. (Japanese)

8) Kato, T., Koike, N., Niibe, H. \& Murakami, Y. (1975) Treatment of cancer of the esophagus by radiation. Nippon Acta radiol., 35, 321-327. (Japanese)

9) Mikuriya, S., Umegaki, Y. \& Seto, T. (1976) Analysis of radiotherapy for esophagus cancer involving the thoracic region. Nippon Acta radiol., 36, 403-419. (Japanese)

10) Nishino, M., Sakurai, T., Sakawa, K., Saito, A., Ibayashi, J., Hamada, M., Koshiba, R., Suzaki, K. \& Hareyama, M. (1978) Intracavitary radium therapy combined with external irradiation for the treatment of esophageal cancer. Jap. J. Cancer Clin., 24, 1099-1105. (Japanese)

11) Pearson, J.G. (1969) The value of radiotherapy in the management of esophageal cancer. Amer. J. Roentgenol., 105, 500-513.

12) Pearson, J.G. (1971) The value of radiotherapy in the management of squamous esophageal cancer. Brit. J. Surg., 58, 794-798.

13) Usui, S., Arai, T., Tsunemoto, H. \& Kurisu, A. (1975) Radiation therapy of carcinoma of the esophagus. Jap. J. Cancer Clin., 21, 43-50. (Japanese) 